\title{
Dialogando com Bernstein e os Tutores da EaD
} Dialogue with Bernstein and the Tutors of the EaD

Thaís Philipsen Grützmann*1, Rozane da Silveira Alves²

1 Professora e Pesquisadora, Departamento de Educação Matemática / Instituto de Física e Matemática / Universidade Federal de Pelotas. Rua Gomes Carneiro, 1, Centro, CEP: 96010-610- Pelotas-RS - Brasil.

thaisclmd2@gmail.com

${ }^{2}$ Professora e Pesquisadora, Departamento de Educação Matemática / Instituto de Física e Matemática /Universidade Federal de Pelotas. Rua Gomes Carneiro, 1, Centro, CEP: 96010-610 -Pelotas-RS - Brasil.

rsalvex@gmail.com

\section{Resumo}

A estruturação pedagógica da Educação a Distância vem sendo analisada sob diferentes enfoques, proporcionando uma gama potencial de pesquisas. Nesta, o objetivo era analisar como o tutor a distância recontextualiza os seus saberes docentes na atuação em Educação a Distância. O lócus de pesquisa foi o Curso de Licenciatura em Matemática a Distância da Universidade Federal de Pelotas. A pesquisa proposta teve caráter qualitativo, sendo definida como estudo de caso. Os sujeitos pesquisados foram os cinquenta tutores a distância do curso. Os dados foram coletados através de questionário online, entrevista semiestruturada e observação não sistemática da prática dos tutores e, posteriormente, analisados através da Análise de Conteúdo e da Teoria de Bernstein. Os principais resultados obtidos foram que a recontextualização dos saberes docentes na prática da tutoria acontece pela reestruturação e reorganização dos conteúdos; pelo tipo de comunicação realizada com os estudantes, principalmente na forma escrita - feedback; pela forma diferenciada com que os materiais e as atividades precisam ser apresentados; e por meio do contato contínuo entre tutor e estudante. A recontextualização também se configura na afetividade e na interação com o aluno que acontece de forma virtual e mais particularizada, mediada pelas tecnologias.

Palavras-chave: Tutor, Educação a Distância, Bernstein, Saberes docentes, Recontextualização. 


\section{Dialogue with Bernstein and the Tutors of the EaD}

\section{Abstract}

The pedagogic structuring of Distance Learning has been analyzed by different approaches, providing a considerable potential for researches. Therfore, the objective was to analyze how the distance tutor re-contextualizes his teaching knowledge in the field of Distance Learning. The research was carried out at the Federal University of Pelotas in the Distance Math Teaching Course. The proposed research had a qualitative approach, being defined as a case study. The subjects researched were fifty distance tutors from the course. The data was collected through online questionnaires, semi-structured interview and a nonsystematic observation of the tutors' practice, and were later analyzed through Content Analysis and Bernstein's theory. The main results obtained were that the re-contextualization of teacher knowledge in the tutoring practice occurs by the restructuring and reorganization of the contents; by the type of communication held with the students, mainly written - feedback; by the differentiated way in which the materials and activities need to be presented and by the continuous contact between the tutor and the student. The re-contextualization occurs in the affectivity and interaction with the student which happens virtually and in a more private setting, mediated by the technologies.

Keywords: Tutor, Distance Learning, Bernstein, Teaching Knowledge, Recontextualization.

\section{Introdução}

O desenvolvimento de cursos na modalidade a distância cresceu vertiginosamente no Brasil, e um dos sujeitos pedagógicos envolvido nesse processo é o tutor. Este pode ou não ter o seu trabalho reconhecido como parte da equipe docente do curso em que atua, definida aqui como polidocência (Mill, 2012). Nessa perspectiva, o texto trará uma reflexão a partir do trabalho desenvolvido pelos tutores a distância, à luz da teoria de Bernstein, buscando traçar um paralelo com a recontextualização dos saberes docentes deles a partir da teoria de Tardif.

A Teoria de Bernstein é rica e profunda, podendo ser explorada sobre dois aspectos: conceitual e metodológico, visto seu poder de diagnosticar, descrever, explicar, prever e transferir. Basil Bernstein é natural da cidade de Londres, nascido em 1924. Começou sua carreira acadêmica na década de 1960 e durante sua vida dedicou-se aos estudos e mostrou particular interesse pela educação, situando-se entre os grandes sociólogos do século XX (Morais, 2004). Em 1958, Bernstein começou a publicar, e o desenvolvimento de sua teoria aconteceu de forma contínua até o ano 2000, quando faleceu. A sequência de suas obras apresentou a evolução do seu pensamento; a única traduzida para português é $A$ estruturação do discurso pedagógico: classe, código e controle, em 1996.

Bernstein é um dos principais representantes da Nova Sociologia da Educação (NSE), cuja principal preocupação era o desenvolvimento de uma sociologia do conhecimento; para isso, investiu em estudos que analisassem as relações entre a organização do conhecimento e a distribuição do poder. Sua preocupação - levou a criar "uma linguagem que, ao gerar descrições específicas das práticas e discursos das relações pedagógicas, possibilitasse o estudo dos processos concretos de transmissão e aquisição de conhecimentos, valores e formas de consciência" (Leite, 2007, p. 23). 
Sua teoria busca compreender o papel da escola no processo de produção, reprodução e mudança cultural e social. O foco está nos processos de socialização do conhecimento, em que busca analisar a comunicação pedagógica.

\title{
Código
}

Código é um conceito central na teoria sociológica de Bernstein. “Como se aprendem as posições de classe? Como as estruturas de classe se traduzem em estruturas de consciência? (...) O código é precisamente a gramática da classe" (Silva, 2009, p. 74). Para Bernstein, “um código é um princípio regulativo, tacitamente adquirido, que seleciona e integra significados relevantes, formas de realização e contextos evocadores" (1996, p. 143). São dispositivos de posicionamento determinados culturalmente. Sua unidade de análise são as relações entre contextos e não um enunciado abstrato ou um contexto isolado. "O código é um regulador das relações entre contextos e, através dessa relação, um regulador das relações dentro dos contextos" (ibidem, p. 143).

Bernstein utiliza o termo "relações de classe" para assinalar diferenças na distribuição do poder e nos princípios de controle entre os grupos sociais. Essas relações "geram, distribuem, reproduzem e legitimam formas distintas de comunicação, as quais transmitem códigos dominantes e dominados, e que, no processo de adquirir esses códigos, os sujeitos são por eles diferentemente posicionados" (1996, p. 28).

Em suas obras sobre linguagem, ele abordaos códigos elaborado e restrito; o conceito de código se refere a um princípio regulador que está na base dos sistemas de mensagens (currículo, pedagogia e avaliação).

\begin{abstract}
Código elaborado se caracteriza por uma ordem de significação universalista, cujos princípios e operações são tornados explícitos e que, estando desligada do contexto, dá ao falante possibilidade de distanciamento e, portanto, de reflexividade; os falantes de um código elaborado tendem a estar cientes das diferenças individuais e a ter papeis menos formalizados. (...) Código restrito se caracteriza por uma ordem de significação particularista, em que os princípios e operações são mantidos implícitos, dado que as significações partilhadas e ligadas ao contexto não carecem de muita verbalização; os falantes de um código restrito tendem a ter papéis comunitários, não estando muito cientes das diferenças individuais (Domingos et al., 1986, p. 343-344).
\end{abstract}

Essas diferenças existem pelo fato de os códigos apresentarem-se de formas distintas em relação à classe social, ou seja, há diferenças entre os códigos de comunicação dos filhos da classe operária e dos filhos da classe média, refletidas pelas relações de classe e de poder na divisão social do trabalho. Essas relações dos códigos são estudadas pelo autor no contexto da sala de aula, visto que a escola reproduz os códigos elaborados, deixando as crianças das famílias das classes operárias à mercê, visto empregarem, em grande parte, somente o código restrito.

O discurso dos professores sempre tem certa superioridade em relação aos discursos dos alunos: ensinar não é apenas dizer alguma coisa, é também dizê-lo de certa maneira, em função dos códigos linguísticos e culturais; esse discurso também manifesta, em suas formas de expressão, o domínio de um certo nível de linguagem (Tardif \& Lessard, 2011, p. 251-252). 
Contudo, o próprio Bernstein salienta que não existem códigos melhores ou piores, superiores ou inferiores, apenas códigos em contextos sociais distintos, códigos culturais diferentes, que merecem ser estudados.

\section{O dispositivo pedagógico}

Para que pudesse fazer a análise da comunicação pedagógica, Bernstein desenvolveu o conceito de dispositivo pedagógico, a partir do conceito de dispositivo linguístico. O dispositivo pedagógico é constituído de algumas regras, entre elas a regra da recontextualização, fundamental nesta pesquisa.

Fundamental porque investigamos quais eram os saberes docentes que os tutores tinham, mobilizaram, construíram e/ou adquiriram, compreendendo como se produziram esses saberes, desde a formação inicial até sua prática na sala de aula presencial e virtual. O foco foi investigar essa recontextualização de saberes que os tutores fizeram ao atuar na modalidade EaD, a partir dos saberes prévios que já produziram, construíram, mobilizaram, adquiriram como professores do ensino presencial.

O discurso pedagógico é definido como sendo um "discurso especializado cujos princípios internos, regulando a produção de objetos específicos (transmissores/aquisidores) e a produção de práticas específicas, regulam o processo de reprodução cultural" (Domingos et al., 1986, p. 346). O discurso pedagógico é um princípio que extrai um discurso de sua prática e contexto de origem e o reloca ajustando-o com seu próprio princípio de focalização e reordenamento seletivos. O discurso pedagógico constrói um discurso específico sobre determinado assunto. Bernstein (1996), então, buscou saber como se constitui esse discurso específico e os princípios da sua transmissão, referenciando-se na gramática. “O discurso pedagógico é composto por um conjunto formado por três regras: de distribuição (que regula o nível de produção), de recontextualização (que regula o nível de transmissão) e de avaliação (que regula o nível de aquisição)" (Lorenz, 2009, p. 58).

Bernstein buscou, com essas três regras, ordenar o aparelho pedagógico, relacionando-as, e, por meio delas, então compreender a dinâmica interna do discurso que é capaz de reproduzir essas relações. Apesar de estar visando à reprodução, isso permite que as coisas aconteçam não exatamente como estavam previstas. O processo que possibilita um espaço para essa contestação na teoria bernsteiniana é exatamente a recontextualização. A recontextualização abre uma margem para encontrar, na ponta do processo educacional, não exatamente aquilo que estava previsto. A recontextualização é o que possibilita a mudança.

A partir do processo de pedagogização do conhecimento, Bernstein se preocupa em "criar uma linguagem conceitual capaz de descrever os caminhos de construção do discurso e da prática das relações pedagógicas, priorizando os contextos escolares e considerando fundamental nesse processo a configuração dos saberes que ali circulam" (Leite, 2007, p. 29, grifos meus). A autora aborda uma questão que chama a atenção, justamente quando fala da "configuração dos saberes que ali circulam". Dentro do ambiente escolar existem as relações de poder e, segundo Bernstein, a partir da segunda regra do discurso pedagógico, a regra de recontextualização, é que são criados seletivamente os sujeitos pedagógicos, mediante um processo de deslocação e recolocação do texto ou do documento. Assim, são definidos, então, como os sujeitos recontextualizadores, responsáveis por fazer as modificações nos textos ou documentos selecionados para serem incluídos no discurso pedagógico.

A partir, então, do princípio de recontextualização, são criados os campos de recontextualização e seus agentes. A teoria do discurso pedagógico é apresentada como um modelo no qual o texto de determinado currículo ou programa manifesta o Discurso Pedagógico Oficial (DPO) produzido no Campo de Recontextualização Oficial (CRO) (Ministério de Educação, por exemplo) como consequência das várias influências dos campos do Estado, do controle simbólico e da economia, bem como de influências internacionais (Morais \& Neves, 2006). Neste campo, o DPO é proposto de uma nova forma, porém também sendo 
influenciado de diferentes maneiras. A ideia não era analisar o currículo vigente, mas sim os saberes docentes de um grupo de sujeitos que compõem a equipe docente do curso, os tutores a distância. Assim, faz sentido que, ao invés de escolher, por exemplo, os programas oficiais do MEC como fonte de dados do DPO, este seja configurado como sendo os saberes da formação inicial dos tutores, adquiridos durante a graduação. Saliento que, mesmo antes dessa formação, já tinham adquirido outros saberes, conforme Tardif (2011) expõe em sua teoria, como a história de vida e a formação escolar anterior, entre outros.

O texto do DPO, considerando um currículo, um programa ou os saberes, sofre um processo de recontextualização no Campo de Recontextualização Pedagógica (CRP), no âmbito das instituições escolares, quando é utilizado na elaboração de livros, manuais ou planos de ensino, por exemplo, passando a assumir-se como Discurso Pedagógico de Reprodução (DPR). De forma semelhante, ao considerar os saberes da formação inicial como o DPO, a recontextualização aconteceu no CRP, sendo este considerado o próprio curso para o qual o tutor foi selecionado para trabalhar. O DPR foram os saberes constituídos na formação que os tutores receberam para atuar na educação a distância, a partir das capacitações. 0 foco desse DPR foi os saberes docentes que ele foi adquirindo, de forma implícita ou explícita, conforme a recontextualização realizada pelos professores. Esses saberes foram do tipo disciplinares, vinculados aos conceitos e conhecimentos específicos, curriculares, conforme o discurso da IES, seus objetivos e métodos, e de formação profissional (ou pedagógicos), relacionados às ciências da educação e à ideologia pedagógica.

No Contexto de Reprodução, como é o contexto da escola ou da sala de aula, quer o texto do programa ou currículo (DPO), quer o texto dos livros, manuais escolares ou planos de ensino (DPR) são objetos de recontextualização ao nível das práticas pedagógicas dos professores. Aqui, a prática pedagógica considerada foi também de alguém que exerce a docência, porém não dos professores e sim dos tutores. A ideia foi que esses tutores, professores licenciados em sua formação inicial, fazem a recontextualização dos saberes docentes que mobilizaram, adquiriram e/ou construíram durante sua trajetória de formação inicial, bem como na trajetória pessoal e profissional e na formação específica recebida pelo curso para atuar como tutor, para os utilizar na atuação docente na modalidade à distância.

Esses processos de recontextualização, que têm lugar sempre que há um deslocamento do texto de um contexto para outro, conduzem a modificações do texto cujo sentido e grau refletem, entre outros fatores, os princípios pedagógicos dos sujeitos dos respectivos campos e as influências resultantes das interações sociais que se estabelecem entre agentes do mesmo campo e de campos diferentes. O texto original, aqui reconfigurado pelos saberes da formação inicial, também sofreu essas modificações, sendo constantemente mobilizado, adquirido e/ou construído, mediante a interação cotidiana com os alunos e/ou demais sujeitos do processo pedagógico, bem como quando da prática docente, que no caso dos sujeitos tutores a distância é realizada praticamente na forma virtual. Esses saberes foram mobilizados, adquiridos e/ou construídos no agir de cada tutor, nas suas experiências pessoais ou profissionais fora do âmbito da EaD. Portanto, "existe assim um potencial espaço de mudança quando se passa de contexto para contexto, ao longo do sistema educativo" (Morais\& Neves, 2006, p. 76). Dessa forma, a recontextualização dos saberes aconteceu, como ilustrada na Figura 1. 


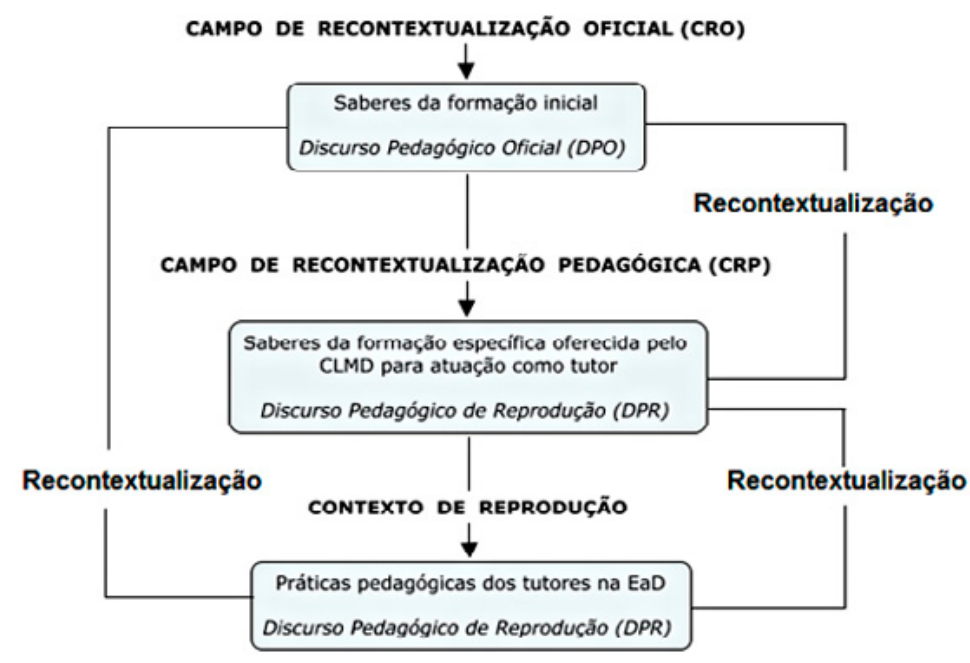

Figura 1: Níveis de recontextualização.

Na pesquisa, partimos da premissa de que o tutor recontextualiza os seus saberes docentes. De que forma? As hipóteses eram relacionadas à comunicação, interação e formas de atendimento ao aluno, vinculadas aos saberes disciplinares, curriculares, de formação profissional e da experiência. Fazendo uma relação com a teoria de Tardif, "ensinar, de certa maneira, é sempre fazer algo diferente daquilo que estava previsto pelos regulamentos, pelo programa, pelo planejamento, pela lição" (Tardif \& Lessard, 2011, p. 43), o que para Bernstein, é recontextualizar.

\section{A Polidocência}

Ao se pensar a estrutura pedagógica de cursos em Educação a Distância, encontram-se variadas personagens que a compõem para que as aulas aconteçam, diferentemente do ensino presencial. Quando se faz referência ao ensino presencial, remete-se à imagem de um único professor em sala de aula com uma turma de alunos. $\mathrm{Na}$ EaD essa realidade é diferente, uma vez que não encontramos um único profissional realizando todo o processo de ensino-aprendizagem, além de o espaço da sala de aula não se constituir como um elemento que reúne, ao mesmo tempo e no mesmo lugar, os estudantes envolvidos no processo. Mill (2012) justifica a peculiaridade do trabalho na EaD com base na quantidade de alunos e da complexidade do processo de trabalho, o que impossibilita, segundo o autor, a unidocência.

Assim, a polidocência é “o trabalho docente virtual [que] é realizado coletivamente (de modo colaborativo e fragmentado)" (Mill, 2012, p. 58) pelo grupo de sujeitos envolvidos no processo de ensino e aprendizagem do curso. E, no contexto de nossa pesquisa, o tutor faz parte da polidocência.

Gonzalez (2005) define o professor-tutor como sendo um profissional docente que possui duas características simultâneas: precisa dominar o conteúdo técnico-científico do curso do qual faz o atendimento e ter habilidade para estimular o estudante a participar e buscar suas respostas. Esse autor busca ressignificar o termo de forma que "trabalhar como tutor significa ser professor e educador" (p. 21).

Fica evidenteque, na EaD, faz-se necessário um trabalho coletivo, com diferentes sujeitos desempenhando distintas funções, que compõem o todo pedagógico, corroborando a ideia de que "o ensino é uma ocupação cada vez mais complexa que remete a uma diversidade de outras tarefas além das aulas em classe" (Tardif \& Lessard, 2011, p. 133). E "é provável que a docência na EaD requeira alguns saberes complementares ou diferentes daqueles da docência presencial" (Mill, Ribeiro \& Oliveira, 2010, p. 54). Mas quais saberes? Como eles são recontextualizados? 


\title{
Saberes Docentes
}

Tardif argumenta que, a partir dos estudos desenvolvidos por ele e seus colaboradores, a noção de saber é ampla, refletida com base na fala dos próprios sujeitos docentes. O saber engloba "os conhecimentos, as competências, as habilidades (ou aptidões) e as atitudes dos docentes, ou seja, aquilo que foi muitas vezes chamado de saber, de saber-fazer e de saber ser" (Tardif, 2011, p. 60).

O autor fala sobre os saberes docentes considerando duas importantes vertentes: o saber dos professores em seu trabalho e em sua formação. Para ele, não se pode estudar o saber docente sem relacioná-lo com os condicionantes e com o contexto em que os profissionais do ensino estão inseridos. Dessa forma, os saberes só têm ou adquirem sentido na sua relação com o trabalho dos professores. O saber docente é um saber sobre o trabalho, para o trabalho e que vem do trabalho. Até mesmo aqueles saberes adquiridos em tempos e espaços anteriores à prática profissional só passam a ter significado quando se encontram, se defrontam com as necessidades profissionais dos professores.

\begin{abstract}
O saber não é uma coisa que flutua no espaço: o saber dos professores é o saber deles e está relacionado com a pessoa e a identidade deles, com a experiência de vida e com a sua história profissional, com as suas relações com os alunos em sala de aula e com os outros atores escolares na escola (Tardif, 2011, p. 11).
\end{abstract}

Assim, este trabalho buscou analisar, à luz da teoria de Bernstein, a recontextualização dos saberes docentes dos tutores construídos durante sua trajetória pessoal, acadêmica e profissional, considerando-os da equipe polidocente.

\section{Metodologia}

A pesquisa realizada teve o caráter qualitativo e foi definida como um estudo de caso no Curso de Licenciatura em Matemática a Distância (CLMD) do Instituto de Física e Matemática da Universidade Federal de Pelotas. Os sujeitos envolvidos foram os 50 tutores a distância do CLMD, à época (em 2013).

A coleta de dados realizou-se em três etapas: através de questionário online, de entrevista semiestrutura e da observação assistemática da prática dos tutores no laboratório, registrada em diário de campo. Para a análise dos dados utilizou-se Análise de Conteúdo.

\section{Resultados e Discussão}

Os resultados apresentados pela pesquisa foram vários, salientando que a recontextualização dos saberes docentes pelos tutores do CLMDde fato aconteceu. Porém, antes de relatar como, gostaríamos de salientar a questão da construção dos códigos por parte dos tutores, conforme as definições de Bernstein.

Os tutores a distância, ao se comunicar com os alunos, assumem postura mais formal, acadêmica, devido ao fato de constituir a equipe docente do curso. Dessa forma, acabam utilizando um código elaborado nessa comunicação, com um vocabulário específico, tanto relacionado à Matemática, área de estudo dos alunos, como um vocabulário específico da EaD, modalidade de ensino ofertada, a qual abrange conceitos tecnológicos e virtuais. Esse código elaborado é, inicialmente, apresentado aos tutores por meio da capacitação oferecida pelo curso quando do ingresso deles para o trabalho na tutoria. Essa gramática dos códigos "Ihes permite distinguir entre os diferentes contextos, distinguir quais são os 
significados relevantes em cada contexto e como expressar publicamente esses significados nos contextos respectivos" (Silva, 2009, p. 74).

Em relação à Matemática, não houve problemas significativos em relação ao código elaborado. Já em relação ao código elaborado para a EaD, a situação foi outra. Como exemplo, duas tutoras que inicialmente demonstravam possuir o código restrito em relação à EaD fazem um relato sobre a capacitação inicial que obtiveram. A Tutora 4 falou: “confesso que, a respeito da capacitação, não foi proveitosa para mim, pois não havia trabalhado ainda com essa modalidade, e muitas informações passadas não soube do que se tratava". A Tutora 8 complementa:

Pra mim não foi muito claro, pois a maioria dos colegas já era tutor há algum tempo e a linguagem e assuntos eram direcionados a eles. Poucos foram os momentos em que pude compreender como funcionava a tutoria. Muito cresci em conhecimento conversando com colegas que já tinham uma caminhada.

O Tutor 25 fala da importância da formação continuada: "é necessário reciclar e atualizar os tutores de novas ferramentas que venham a surgir, assim como softwares que venham a ser utilizados com os alunos antes de iniciarmos o semestre ou módulo", buscando a melhoria do código elaborado na EaD.

Quando fazemos referência aos alunos, de acordo com a própria percepção dostutores, ficou evidente a carência sobre os conhecimentos referentes aos códigos elaborados vinculados à EaD e às tecnologias. E essa diferença não é somente de classe social, como Bernstein (1996) expõe em sua teoria. Quando se trata de alunos de EaD, no contexto do CLMD, a faixa etária média é mais avançada, e, dessa forma, mesmo alunos pertencentes a uma classe social com maior poder aquisitivo e cultural encontram dificuldades oriundas dos contínuos avanços tecnológicos.

Porém, conforme tutores e alunos foram desenvolvendo uma relação mais próxima e construíram uma comunicação eficaz entre si, percebeu-se a construção dos códigos elaborados necessários para o bom desenvolvimento do curso, ou seja, ambos aprenderam essa nova linguagem da EaD. A interação e a comunicação se realizaram, então, de forma tranquila e fluente.

A recontextualização dos saberes docente dos tutores a distância aconteceu e pode-se relacioná-la à teoria de Bernstein em vários aspectos. "Entendo [a recontextualização] como uma reflexão das práticas adotadas em determinados momentos, alterando a metodologia utilizada quando necessário", afirma o Tutor 13. Na fala desse tutor pode-se resumir boa parte dos resultados da pesquisa, pois afirma que, sempre que necessário, fizeram mudanças, adaptações,recontextualizações para atender os acadêmicos da forma mais produtiva.

Primeiro, cabe salientar que o discurso da prática desses professores, vivenciada nas escolas, foi relocada, agora para o ensino superior, em uma função de membro de equipe docente e não mais como docente exclusivo da turma. Corroborando esse resultado, apresentamos a fala daTutora 7, que, por trabalhar com a Educação Básica, acabou precisando retomar os conteúdos do ensino superior. "Eu revi muita coisa porque, como eu parei muito tempo, fiquei muito tempo afastada do ensino superior; eu revi todos os conteúdos ali na tutoria até pelas próprias perguntas que os alunos faziam",pois é imprescindível que o tutor tenha pleno conhecimento da matéria a ser ensinada, um saber descrito por Tardif (2011).

A partir desse novo contexto de atuação, os tutores se viram obrigados a repensar sua prática, desde sua linguagem, como descrito acima, em função dos códigos restritos e elaborados, como em relação à sua formação e ao trabalho em equipe. Eles se viram reestruturando e reorganizando os conteúdos a serem desenvolvidos com os alunos, pois na EaD é necessário que estes desenvolvam a capacidade 
de estudar sozinho ou, então, com o auxílio da tutoria a partir de mediação tecnológica. Assim, simples resoluções de exercícios ganharam explicações detalhadas, um guia passo apasso para o estudo, diferentemente do ensino presencial, em que muitos detalhes são apenas verbalizados em aula, mas não escritos pelos professores nos materiais disponibilizados. A apresentação dos conteúdos de forma diferenciada acaba sendo vinculada ao mundo virtual, que exige essas mudanças:

A abordagem virtual necessita dessa recontextualização, e a EaD usa ferramentas que não são as usuais em se tratando de ensino presencial. Um exemplo disso é o trabalho com editores de texto não convencionais, visto que sua utilização é de muita importância para a escrita matemática, isso sem falar de tantos outros softwares utilizados durante a tutoria (Tutor 35).

Recontextualizar a comunicação é algo que também foi muito discutido na tutoria. Os tutores e alunos conversam por textos, em fóruns, e-mails, chats ou feedbacks. Em sala de aula, a comunicação é praticamente oral; na EaD ela é transformada em comunicação escrita. O Tutor 34 comenta isso, falando de uma característica indispensável: “E mais: se ele tem a capacidade de se comunicar e se conectar com uma pessoa que ele não conhece, com quem ele não consegue interagir fisicamente". Como não magoar o aluno e ao mesmo tempo mostrar-Ihe um erro? Essa e outras preocupações precisam ser superadas na EaD quando se trata da comunicação, essencial para qualquer tipo de relacionamento.

A linguagem escrita dos tutores, muitas vezes no feedback enviado aos alunos, é um saber que foi construído pela equipe: "tenho que me expressar de um modo claro e formal para digitar as respostas referentes a uma dúvida do aluno", afirma a Tutora 4. "O feedback que mediatiza a aprendizagem é aquele colocado de forma clara, direta, por vezes orientando discursivamente, por vezes por meio de perguntas ou de uma breve indicação ou sugestão" (Masetto, 2009, p. 166).

Eu tive que adquirir e movimentar mais foi na questão de dar os retornos de forma clara e objetiva (...). E a cada novo feedback parecia que ele ficava mais fácil de ser escrito. É a prática, eu acho (...). Então, pra mim, essa aprendizagem de escrever, ler e reescrever feedbacks pra dar o retorno pros alunos eu acho que foi um conhecimento que eu precisei adquirir e ao mesmo tempo readquirir a cada novo feedback, uma coisa que 'tava sempre em movimento contínuo, porque as atividades eram muito diversas (Tutor 13).

A recontextualização também se configurou na afetividade e na interação com o aluno, que acontece de forma virtual e mais particularizada, mediada pelas tecnologias. A Tutora 7 fala dessa questão como uma habilidade essencial: "eu acredito que tenha que ser o lado mais doce no sentido de chamar atenção, mas de uma forma delicada pra não aumentar os problemas".É a preocupação de ensinar ao aluno de forma correta, mas cuidando do outro lado - o sentimento, a emoção, o psicológico de cada estudante.

"O trabalho docente constitui uma das chaves para a compreensão das transformações atuais das sociedades do trabalho" (Tardif \& Lessard, 2011, p. 17); logo, é importante refletir sobre ele na EaD. Pode-se pensar a Educação a Distância, modalidade de ensino em expansão principalmente nas últimas décadas, como uma das responsáveis pelas modificações relacionadas ao trabalho docente. Na EaD não existe somente a figura do professor, mas sim uma equipe polidocente responsável pela execução de todo o trabalho pedagógico vinculado ao processo de ensino e aprendizagem, na qual merece destaque a figura do tutor, responsável também pela recontextualização dos saberes docentes no cenário atual. 
Essa recontextualização acontece com toda a equipe, em vários momentos e de várias formas. O gestor e a equipe pedagógica precisam conhecer a realidade do curso e de cada grupo de alunos nos polos para tomar as decisões mais acertadas, pensando sempre no sucesso do processo de ensino e aprendizagem de cada estudante e o do coletivo, em geral.

\section{Considerações Finais}

A Educação a Distância consolidou-se e, a partir disso, precisamos cada vez mais entender como os sujeitos da equipe pedagógica atuam, quais são seus saberes ede quais recursos e tecnologias precisam para preparare executar aulas de qualidade. A proposta de reflexão a partir das teorias de Bernstein, Mill e Tardif é apenas um viés. Percebe-se que o cenário de expansão do ensino superior está vinculado à EaD e que o tutor, em muitas instituições, tem papel atuante no processo de ensino e aprendizagem, permeando as equipes pedagógicas e fazendo refletir sobre o trabalho docente e seus entrelaçamentos nos dias atuais.

A recontextualização dos saberes docentes aconteceu com os tutores a distância em diferentes aspectos, como descrito. Só isso já faz pensar em como está a docência e quais seus caminhos futuros. Mas podemos ir além: será que essa recontextualização de fato ocorre com toda a equipe envolvida na polidocência? Se sim, como afeta o planejamento e a execução dos cursos?

A reflexão sobre esses fatores vinculados aos saberes docentes pode trazer à tona outras discussões: e a precarização do trabalho docente? E o tutor, sendo professor, que relação tem com as IES, se é somente um bolsista? A carga de trabalho é a mesma, se comparada ao ensino presencial, se além do momento oficial das aulas tem-se um ambiente virtual para acompanhar diariamente?

É importante que, ao se pensar o processo de ensino na EaD, as equipes pedagógica e administrativa busquem refletir também sobre todos os sujeitos envolvidos e cada um dos processos de trabalho, especialmente adocência. E, a partir dela,refletir continuamente sobre como melhorar, como cada um pode atuar de forma eficiente para que o aluno seja o grande beneficiado do processo.

\section{Referências Bibliográficas}

Bernstein, B. (1996). A estruturação do discurso pedagógico: classe, códigos e controle. Petrópolis: Vozes.

Domingos, A. M. et al. (1986). A teoria de Bernstein em Sociologia da Educação. Lisboa: Fundação Calouste Gulbenkian.

Gonzalez, M. (2005). Fundamentos da tutoria em educação a distância. São Paulo: Avercamp.

Leite, M. S. (2007). Recontextualização e transposição didática: introdução à leitura de Basil Bernstein e Yves Chevallard. Araraquara: Junqueira \& Marin.

Lorenz, V. E. (2009). Arte e conscientização ambiental: uma reflexão sobre a formação continuada de professores, fundamentada em Basil Bernstein. Tese (doutorado). Universidade Federal do Rio Grande do Sul.

Masetto, M. T. (2009). Mediação pedagógica e o uso da tecnologia. In J. M. Moran, M. T. Masetto, \& M. A. Behrens (Org.). Novas tecnologias e mediação pedagógica. $15^{\mathrm{a}}$ ed. Campinas: Papirus.

Mill, D. R. S., Ribeiro, L. R. C., Oliveira, M. R. G. (Org.) (2010). Polidocência na educação a distância: múltiplos enfoques. São Carlos: EdUFSCar.

Mill, D. R. S. (2012). Docência virtual: uma visão crítica. Campinas: Papirus. 
Morais, A. M. (2004). Basil Bernstein: Sociologia para a Educação. In: A. Teodoro, C. Torres (Org.). Educação crítica \& utopia: perspectivas para o século XXI. Lisboa: Afrontamento.

Morais, A. M. \& Neves, I. (2006). Processos de recontextualização num contexto de flexibilidade curricular - análise da actual reforma das ciências para o ensino básico. Revista de Educação, (XIV) 2, 75-96.

Silva, T. T. (2009). Documentos de identidade: uma introdução às teorias do currículo. $3^{\text {a }}$ ed. Belo Horizonte: Autêntica.

Tardif, M. (2011). Saberes docentes e formação profissional. 12ª ed. Petrópolis: Vozes.

Tardif, M. \& Lessard, C. (2011). O trabalho docente: elementos para uma teoria da docência como profissão de interações humana. $6^{\mathrm{a}}$ ed. Petrópolis: Vozes. 